\title{
Para leer, es necesario escribir. Entrevista con Francisco Cajiao
}

\section{To read, you need to write. An interview with Francisco Cajiao}

DOI: https://doi.org/10.32870/dse.v0i23.1077

\section{Por Diana Sagástegui Rodríguez}

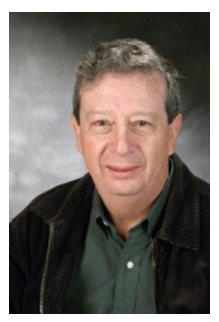

Francisco Cajiao es Licenciado en Filosofía de la Universidad Javeriana y Maestro en Economía por la Universidad de los Andes. Se ha desempeñado como docente por más de veinticinco años, tanto en la escuela primaria y secundaria como en el ámbito universitario, donde ocupó la rectoría de la Universidad Distrital y de la Universidad Pedagógica Nacional. Fue director del Departamento Administrativo de Bienestar Social del Bogotá. Trabajó durante cerca de diez años como consultor de las Naciones Unidas en El Salvador, Guatemala, Nicaragua, Roma y Mozambique. También ha sido consultor de UNESCO en Perú y de la CAF en los países del área andina. Durante diez años fue director de la División de Educación de la Fundación FES, desde donde impulsó grandes proyectos de investigación y desarrollo escolar como Atlántida, Nautilus y Pléyade. Asesor de COLCIENCIAS para el Programa ONDAS de Ciencia y Tecnología. Secretario de Educación de Bogotá (2005-2007). Fue rector de la Universidad de CAFAM (2012-2018). Es miembro permanente de la Academia Colombiana de Pedagogía y Educación. Actualmente funge como asesor del Ministerio de Educación. Francisco Cajiao ha desarrollado una amplia labor en investigación educativa. Además de ser columnista permanente del importante periódico El Tiempo, ha publicado numerosos artículos en revistas especializadas. Es autor de varios libros: Poder y justicia en la escuela colombiana, Pedagogía de las Ciencias Sociales, Las fronteras de la normalidad, La piel del alma, La formación de maestros y su impacto social, e Instrumentos para escribir el mundo. Su libro más reciente es La identidad de los maestros frente al cambio social.

\footnotetext{
* Doctora en Educación. dianasagastegui@yahoo.com
}

Leer no es más que una forma humana de habitar el mundo [...]. Se puede ser analfabeto en el sentido convencional y "leer" sin titubeos el nombre de la leche, la marca de la bicicleta, distinguir si un televisor es Sony o Samsung... Basta sólo un poco de tiempo bajo la influencia 
visual de las vallas publicitarias, los empaques de productos, los gingles de la radio y los video-clips de la televisión para volverse un hábil lector [...]. Riqueza y pobreza humanas son términos que guardan estrecha relación con la necesidad mayor o menor de escribir y leer. Son más pobres los que necesitan muy poco de la lectura, porque eso significa que los mundos en que habitan requieren pocas palabras para ser ocupados: quizá sea suficiente conocer nombres y marcas de productos, rutas de buses, nombres de calles...

Francisco Cajiao $^{1}$

Libros y lectura son constitutivos esenciales de las agendas políticas y culturales por estar reiteradamente asociados al mejoramiento social, económico y democrático de países y pueblos. Muestra de ello, nos encontramos el Año Iberoamericano de las Bibliotecas, con el lema "Bibliotecas que Crean Futuros". ${ }^{2}$ En México, entre otros hechos históricos importantes de la historia de nuestro país, en 2021 se conmemora un siglo de la creación de la Secretaría de Educación Pública, ${ }^{3}$ que desde sus inicios se propuso auspiciar una amplia producción editorial que fuera accesible a toda la población.

En estos cien años se ha librado una lucha frontal para lograr, no solo una alfabetización universal, sino inscribir la lectura como una práctica cultural cotidiana en la vida de todos los mexicanos. Para este efecto se han impulsado, junto con otras instancias gubernamentales y asociaciones, numerosos programas de fomento a la lectura, para consolidar una tradición que ha echado profundas raíces y logrado indiscutibles frutos, si bien se mantienen aún irresueltos desafíos importantes. ${ }^{4}$

Estrategias en esta materia seguidas en otros países de Latinoamérica parecen adoptar directrices similares. Sobre esta cuestión versó la entrevista sostenida en marzo de 2021 con Francisco Cajiao Restrepo (Bogotá, 1947), estudioso apasionado de prácticas de lectura y escritura, decidido impulsor de programas para su fomento, dentro y fuera del entorno escolar.

1 Cajiao, F. (2005). Instrumentos para escribir el mundo. Lectura, escritura y política en el universo escolar. Bogotá: Editorial Magisterio, 38-40.

2 Declarado así en la XX Conferencia Iberoamericana de Ministras y Ministros de Cultura, llevada a cabo en Bogotá, Colombia, el 17 y 18 de octubre de 2019.

3 La Secretaría de Educación Pública fue creada el 3 de octubre de 1921.

4 La persistencia del analfabetismo es uno de ellos. El Censo de Población y Vivienda 2020 (INEGI, 2021) registra un 4.7\% de población analfabeta (definida como persona de 15 años o más que no sabe leer y escribir un recado), lo que equivale a 4'456,431 personas (5.5\% en población femenina; 3.9\% en población de género masculino), ubicados fundamentalmente en los estados de la federación con mayores índices de marginación (Chiapas, Oaxaca, Guerrero), afectando particularmente a adultos de la tercera edad, etnias indígenas y personas que presentan algún tipo de discapacidad. Otra cuestión preocupante es el bajo desempeño en materia de comprensión lectora. Por otra parte, la pandemia de Covid 19 tiende a agudizar los problemas: en la Encuesta para la Medición del Impacto COVID-19 en la Educación (ECOVID-ED) 2020, (INEGI, 2021) se indica que 33.6 millones de personas entre los 3 y 29 años estuvieron inscritas en el ciclo escolar $2019-2020$ (62.0\% del total). De ellas, 740 mil (2.2\%) no concluyeron el ciclo escolar: $58.9 \%$ por alguna razón asociada a la Covid-19 y $8.9 \%$ por falta de dinero o recursos. Se indica además que por motivos asociados a la Covid-19, o por falta de dinero o recursos, no se inscribieron 5.2 millones de personas (9.6\% del total de 3 a 29 años) al ciclo escolar 2020-2021. Los motivos son diversos: $26.6 \%$ considera que las clases a distancia son poco funcionales para el aprendizaje; $25.3 \%$ señala que alguno de sus padres o tutores se quedó sin trabajo, $21.9 \%$ carece de computadora, otros dispositivo o conexión de Internet. 
Iniciamos nuestra conversación preguntando cuál sería la recuperación que podría hacer sobre las experiencias llevadas a cabo en su país.

Francisco Cajiao: En Colombia se ha hecho un gran esfuerzo desde hace mucho tiempo con algunos programas, algunos incluso inspirados en experiencias llevadas a cabo en México, lo mismo que otras diseñadas para gestionar situaciones particulares. Yo me atrevería a decir que, hasta ahora, no tenemos una diferencia en resultados mayor que lo que sucede en otros países de América Latina. Y es porque la lectura está muy arraigada con tradiciones culturales, al igual que con un proceso de escolaridad específico. En el caso colombiano, se tuvo un atraso muy pronunciado en cuanto a cobertura y calidad educativa en comparación con otros países latinoamericanos. Por razones históricas y políticas muy complicadas, su grado de desarrollo estuvo muy atrás de Argentina, de Uruguay; hasta la primera mitad del siglo XX, estuvo cercano a niveles de países como México o Chile. Es a partir de la década de los años ochenta y noventa que se trabaja para revertir este rezago, privilegiando sobre todo la cobertura en la educación básica y luego, con la reforma constitucional en 1991, para establecer la obligatoriedad de la educación hasta el noveno grado. Es en ese momento cuando surgen diversos programas de lectura y escritura, se estimula la creación de bibliotecas escolares, y en las principales ciudades del país como Bogotá, Medellín, Barranquilla, empiezan campañas de lectura impulsadas por las administraciones locales. Algunos buenos resultados se han identificado en posteriores encuestas, si bien con segmentaciones demográficas importantes. Hacia los años 2005-2006, los seguimientos muestran que los niños empiezan a consumir más materiales de lectura que los adultos. A esto corresponden dos cuestiones, en el caso de Bogotá: por una parte, la construcción de grandes bibliotecas públicas en zonas populares de la ciudad, donde además se empiezan a incorporar elementos diversos, en soportes de video y audio, siguiendo el ejemplo de las grandes bibliotecas del mundo donde ya no solamente se encuentra un acervo de libros, sino diversas formas de mantener la memoria cultural. Y, por otro lado, se desarrollan estrategias para estimular a los niños a leer. Una de ellas, la de Libro al Viento, se realiza mediante el acceso a libros de formato muy pequeño, de muy bajo costo, que se distribuían en los colegios cada mes, de tal manera que los niños pudieran además intercambiarlos. Los libros eran para que ellos los tuvieran como acervo, no eran para ponerlos en alguna biblioteca escolar. En Bogotá, estos mismos libros se llevaron al transporte masivo, de manera que, en las estaciones del Transmilenio [transporte público], la gente podía tomarlos y llevárselos para leer en el trayecto y dejarlos luego en cualquier estación, ya habiéndolos leído. Esto provocó una gran circulación de libros de textos breves de grandes autores, de manera que fuera para muchos una entrada a la literatura universal y que, por esa vía, se retomara en las aulas de clase. Hubo otras iniciativas. En Medellín, diversas organizaciones civiles crearon desde entonces, y se mantienen hasta la fecha, grandes clubes de lectura y la realización de congresos nacionales. Con estas estrategias, los niños sí se 
acercan más a la lectura, si bien no hay efectos importantes en los números totales; la población adulta sigue leyendo muy poco, en lo que a libros se refiere. En un lapso de 10 años, ha pasado de 1.9 libros al año que lee el conjunto de la población a 2.5. Ahora bien, por estratos etarios y socioeconómico encontramos por supuesto muchas variaciones. Lo que hay que tener en cuenta es que la lectura en los últimos años se desplaza a los dispositivos móviles; niños y jóvenes leen incesantemente los mensajes que se mandan entre ellos o a quien ellos "siguen". Las redes sociales son a la vez entramados permanentes de lectura y escritura, con otro gran espectro de contenidos audiovisuales en imagen y video. El cine, la televisión, los programas vía streaming, comportan una cantidad de información enorme y con una velocidad que dificulta la capacidad crítica de lectura. Si en lo que toca a la lectura convencional debe reconocerse que, a pesar de algunas buenas experiencias que deberán seguir madurando, no hay avances gigantescos, otras plataformas para lectura y escritura donde igualmente se generan conocimientos y significados sobre la realidad toman la delantera. Desafortunadamente, la escuela se mantiene de espaldas a esta situación.

DSR: ¿De qué manera imaginar una escuela que se posicione de frente ante estas dinámicas de consumo cultural?

Francisco Cajiao: Pues debe pensarse a sí misma y resolver de qué manera puede proveer herramientas para entender el mundo que actualmente se vive, no un mundo que ya pasó. No habrá solamente que considerar la importancia de estas formas de producción y circulación de materiales y de información, sino develar sus lógicas de funcionamiento, favorecer el entendimiento de su gramática, de su sintaxis. Porque son tanto formas de conocimiento como de desinformación, en temas diversos e importantes, como lo muestran desafortunadamente una infinidad de casos, por ejemplo, las explicaciones que circulan sobre la pandemia de Covid-19, donde se mezclan datos verdaderos y falsos, especulaciones y francas mentiras. Podemos preguntarnos, qué está haciéndose desde la escuela y si los profesores conocen e intervienen sobre estos contenidos y modelos de lectura y escritura que se comparten. Pero sucede más bien que desde la escuela los combaten, al prohibir que en ella se use el teléfono móvil, o que los estudiantes consulten y sometan a evaluación ciertas fuentes. Es una salida más fácil que incorporar estas dinámicas en un modelo educativo interesado en estas prácticas de lectura y escritura. Con la actual situación de pandemia, se hizo patente esta situación; aunque aparentemente se hizo un viraje radical al depender de los medios electrónicos para mantener las clases escolares, ni los profesores ni los estudiantes, las formas de utilización se circunscribieron principalmente a la interacción comunicativa más puntual sobre contenidos escolares específicos. Hasta ahora no es claro cómo se están incorporando al trabajo escolar los dilemas que plantean estas prácticas de lectura y escritura. 
DSR: ¿Puede pensarse que profesores, estudiantes y responsables de las directrices o incluso las políticas públicas en el sector educativo pueden sentirse impotentes frente al poder de redes $u$ plataformas digitales? ¿Que quizá entienden cada vez mejor las racionalidades de estas formas de comunicación, gobernadas por los modelos de negocio de las grandes corporaciones tecnológicas, la influencia maliciosa de los algoritmos que deciden qué información llega a cada quien, de manera incluso sesgada, pero que a la vez consideren prácticamente imposible empatar estos poderosos mecanismos con los procesos educativos escolares, sometidos además a reducidos márgenes de acción?

Francisco Cajiao: Esta tensión es una cuestión cultural de una escala mayor, sin duda. Pero lo cierto es que sucede lo mismo con el mundo de lo escrito. Las editoriales pueden publicar cosas de diferente calidad y uno puede leer libros de autoayuda o leer a Shakespeare. Acceder a ediciones descuidadas o bien a obras sublimes. Entonces lo importante no es lo que hay, sino la capacidad de discernir, de elegir. Y justamente, esa capacidad crítica consiste en asignarle un valor a lo que uno desea consumir. Definitivamente, la escuela no está en capacidad de influir en qué y cómo circula información en el entramado de comunicación digital, pero sí puede ofrecer una educación para cultivar el gusto, por ponerlo en términos estéticos. Pero también en la formación de criterio. Un joven puede entrar, digamos, a YouTube y buscar y encontrar información de calidad y relevancia muy distintas. ¿De qué dependen entonces sus trayectos? Si la escuela no tiene la capacidad de realizar este encantamiento para que se encuentre placer por las cosas que enriquezcan su imaginación, pues no se va a lograr tampoco con campañas para promover prácticas de lectura tradicionales, para las que, además, ningún país tiene el dinero suficiente. Es una labor de día a día para la que la escuela está llamada a asumir un papel central. La gran pregunta que nos hacemos acá -yo me la hice muchas veces siendo Secretario de Educación de Bogotá- es acerca de lo que leen los maestros. Muchas veces encontramos que no son lectores apasionados. Están sujetos además a jornadas de trabajo muy intensas, se les obliga a dictar una clase tras otra para seguir posteriormente en casa con tareas de revisión y calificación de trabajos escolares. No son las mejores condiciones para tener una vida cultural amplia, de modo que puedan incorporar en su labor pedagógica ciertos elementos de consumo cultural con lo cual se pueda avivar el gusto por parte de los estudiantes, para guiarlos en búsquedas de información, a partir de ciertos criterios.

DSR: Esto nos lleva a las especificidades de la lectura y la escritura solicitadas en la escuela para generar conocimientos específicos. Hoy día, al menos en lo que a la educación básica concierne, el fiel de la balanza para la búsqueda de información resulta ser frecuentemente Google, cuyos algoritmos, como sabemos, operan mayormente bajo el signo del lucro. En investigaciones que yo he realizado en educación media superior en el estado de Jalisco, encontramos que, inde- 
pendientemente de asignaturas, tipos y ubicación de planteles o estrato socioeconómico de los estudiantes, estos siguen criterios marcados por un protocolo de lectura que puede llamarse genéricamente "escolar": para estudiar y realizar trabajos escritos, los estudiantes buscan la información que coincida con lo que se vio en clase, con lo que les piden específicamente sus profesores o con las cartas descriptivas de sus asignaturas. Realizan de este modo una suerte de "domesticación" de la abundante y diversa información disponible en línea; la biblioteca escolar o el libro impreso se utilizan con mucho menor frecuencia.

Francisco Cajiao: Es preciso examinar cambios culturales muy importantes, fundamentales, que han venido sucediéndose y transforman el contexto de la lectura. Siempre nos ha sido necesario descifrar signos, pues lo que nos hace humanos es esa capacidad de generar sentido. Para ello, nos servimos de lenguajes, que son distintos para los muy diversos contenidos que existen, por decir un ejemplo, el lenguaje matemático, con especificidades muy propias. También podemos advertir la dimensión espacial: las personas cada vez viven más en ciudades, donde los espacios para vivir se han reducido significativamente: una cuestión de metros cuadrados. Personas de mi edad, con bibliotecas extensas no pueden trasladarse fácilmente a otros sitios, como las generaciones más jóvenes tendrán más dificultad para disfrutar del espacio que requiere una biblioteca en casa. Leer en una tablet es distinto a leer en un libro impreso. En la Roma antigua, para leer, había que ir a las grandes edificaciones, y saber latín. Lo importante aquí es qué significados estamos originando e intercambiando, qué conocimientos estamos generando, qué mundo estamos escribiendo. Por supeuesto, todo el conocimiento del mundo actual pasa por la lectura y por la escritura. Todo el universo audiovisual con el que estamos interactuando pasa antes por la lectura y la escritura. Una película requiere la escritura de un guion, que luego debe ser leído por directores, actores y responsables de aspectos artísticos y técnicos para traducirlo en lenguaje audiovisual. Al guiarnos por sistemas de georreferenciación, leemos instrucciones y mapas de modo distinto al habitual en pasado. Es un interjuego permanente entre signos y significados. Entonces, para que el maestro no decida por mí, para que Google no decida por mí, para que al leer un periódico no decida otro por mí, debo desarrollar mi criterio, poder tomar distancia y leer entre líneas. Más aún: no se puede hacer eso si no se comprende cómo se escribe un periódico. Si la escuela quiere enseñar cómo leer un periódico, pues tendrá que hacer uno. Por eso la tesis es: si yo quiero aprender a leer, primero tengo que aprender a escribir. Tengo que explorar las claves -de diversos tipos- que posibiliten lo que quiero decir. Sin tomar de manera literal la cuestión entre qué fue primero, si el huevo o la gallina, la escritura precedió sin duda a la lectura. Se lee algo que ya fue escrito. Y, por otra parte, hay que considerar que quien escribe ejerce un poder mayor a quien solo lee. Pensemos en la escritura de las leyes, o de los libros sagrados, dictados figuradamente por un dios. Lo mismo ocurre en política como en cuanto conocimiento en general: la autoría de un texto que es reconocido, es autoridad. No 
solo es la lectura un desciframiento de signos sino una forma de relación social donde se abren además vías para generar nuevos significados, que pueden transitar por la vía de la imposición, o de apertura a nuevas constelaciones de conocimiento. Esto último puede verse en el caso de la ciencia.

DSR: Sin duda, en todas sus modalidades, las prácticas de lectura y escritura crean vínculo social, civilización, una cultura escrita. Ahora bien, asistimos a un desplazamiento importante con el actual exceso de información, las múltiples y a veces poco éticas estrategias para ganar la batalla por la atención de los lectores en los entornos comunicativos, las mutaciones en las formas de autoría, de clasificación y reconocimiento de lo escrito, la posibilidad de una intertextualidad casi infinita. ¿Nos encontramos ante una posible atomización de producir significados compartidos, al menos al interior de una comunidad interpretativa identificable?

Francisco Cajiao: Esto nos coloca en el universo más amplio de la cultura y de diferentes temporalidades. Recuerdo que hace cuatro o cinco años, en un museo de Roma se montó una exposición de un pintor de la época del Renacimiento cuya obra no había sido apreciada y catalogada sino hasta el siglo XIX. En el mundo de la cinematografía, obras maestras pudieron ser fracaso en la taquilla, pocos asistieron a verlas. En el campo científico, abundan los casos de personas que aportaron conocimientos importantes y que les fueron reconocidos -si acaso- mucho tiempo después. En contrapartida, en el presente, los llamados influencers marcan pautas de socialización y de consumo cultural a condición de su continua actualización. En la política, el éxito no está dado por las propuestas de acción más sólidas, sino las más acordes con lo que las personas quieren oír en un momento dado, y que en casos como la elección de Donald Trump, pueden poner en riesgo el planeta entero. El dilema de cómo discernir entre varias propuestas, en diferentes campos no puede estar resuelto, sino con una educación que habilite para hacer distinciones. Pero las fuentes de sentido más pujantes dependen de muchos factores, lo que es motivo de preocupación. Si se compara la temporalidad para que algo se vuelva viral, con obras de Dostoievski, escritas a mano, con plumas mojadas en la tinta, hablamos de un proceso de años para su producción y puesta en circulación. Ahora la publicación se agiliza y la demanda de libros de escasa calidad, de autoayuda, esotéricos, etc., pueden liderar la demanda. La cuestión aquí es qué es lo que se busca por parte de los públicos, qué necesidades de conocimiento se aprecian, cómo se cubren, en qué marcos de significado se desea afiliarse.

DSR: Es frecuente encontrar el argumento de la funcionalidad en las prácticas de lectura y escritura, que las muestran como un fin loable en sí mismas. Se puede escuchar, por ejemplo, que la literatura de obras orientadas al entretenimiento -como los best sellers sobre zombis, magos, etc.- han ayudado a que la población juvenil desarrolle el gusto por la lectura. Se ha documen- 
tado un giro en la oferta de la industria editorial, que justifica su apuesta por publicar obras cortas, recreativas. ¿Nos lleva esta situación a replantear el "para qué" leer hoy día?

Francisco Cajiao: Si me preguntas por qué leer, en términos humanos es como si me preguntaras por qué respirar. Si no se lee, no hay posibilidad de integrarte en un tejido social que está fundamentalmente hecho de cultura escrita. Pero la pregunta tiene sentido, para responderse con algunos matices. ¿Qué razones hay para leer una novela, si la vida de cada uno es a fin de cuentas una novela ambulante, porque a todos nos pasan todo tipo de cosas? Al respecto, Sábato afirma que toda la filosofía latinoamericana está en la novela. Las obras de Fuentes, García Márquez, Borges, por ejemplo, muestran cómo significan el mundo las personas en nuestros países. Podemos citar otros autores: de etnias indígenas o a escritoras mujeres, que muestran una visión que les es propia. Y habría que estimular también que escriban los jóvenes, los adolescentes. Leer es la posibilidad de interpretar el mundo y dar lugar a la empatía con otros, similares y diferentes. Leer para aprender ciencias sociales me permite entendimiento sobre por qué somos como somos, las causas de pobreza, exclusión, la concentración progresiva del poder y la riqueza a nivel mundial, por citar un caso. Y así podemos mencionar otros campos de saberes, que constituyen todos invaluables instrumentos de intelección. En Colombia, el programa Ondas de Ciencia y Tecnología, iniciado dos décadas atrás y donde tuve el privilegio de participar, estuvo dirigido a formar niños y adolescentes para desarrollar proyectos de investigación y apoyarlos financieramente. Hoy ya se cuentan en este lapso más de 35 mil grupos de investigación de estudiantes que van entre los 5 y los 18 años. De allí surgieron a lo largo de este tiempo vocaciones y carreras de investigadores hoy día ya consagrados. Pero, sobre todo, ha sido un terreno de libertad para la lectura y la escritura con base en la autonomía de los sujetos, para decidir sus intereses, articulada con su pasión por saber, por entender el mundo. La escuela necesita trabajar en esta dirección.

Cerramos esta entrevista con claridades importantes. Las acciones y estrategias institucionales encaminadas a hacer de la lectura y la escritura una parte de la vida cotidiana requieren diseñarse con el pleno reconocimiento de que lo crucial en ellas es impulsar, por intermediación de prácticas de literacidad, ${ }^{5}$ la capacidad de agencia de los sujetos para discernir y participar en el mundo

5 Se entiende por literacidad un conjunto de prácticas sociales concretas y situadas, asociadas a la lectura y escritura, inscritas en determinados contextos sociales cuyas modalidades y consecuencias se definen en conjunto con un amplio ensamblaje de factores políticos, económicos y sociales, incluida la cultura del grupo de referencia. Street, B. (1984) Literacy in Theory and Practice. Cambridge, Mass: Cambridge University Press. Judith Kalman advierte los inconvenientes que representa usar este neologismo, traducción literal del inglés, cuya utilización resulta sin embargo necesaria debido a la insuficiencia del significado de su traducción al castellano -alfabetismo- muy cercana a la palabra alfabetización, que denota generalmente una concepción individual de adquisición y manejo de convenciones gráficas y las implicaciones negativas asociadas al analfabetismo, soslayando que la literacidad implica "aprender a participar en las actividades sociales o eventos comunicativos donde se utiliza la escritura; es decir, aprender a hablar acerca de su uso y forma, comprender el significado del 
que les es propio. En esta posibilidad se destaca el carácter de práctica sociocultural que poseen tanto las prácticas vernáculas que permiten ser funcionales en ámbitos concretos, como las que se realizan exclusivamente por el placer que se deriva de leer, y aquellas enfocadas al dominio de contenidos académicos, artísticos o disciplinares.

La escuela juega un papel protagónico para el logro de este propósito fundamental, en la medida en que sus objetivos educativos están orientados al desarrollo de capacidades cognitivas y competencias de interacción social. Pero también es debido al rol determinante que adquiere la literacidad escolar como el modelo válido o deseable, por su mayor cercanía a regímenes de cientificidad y a los cánones clásicos de la cultura letrada. ${ }^{6}$ Los contenidos escolares presentan tradicionalmente exigencias de coherencia discursiva, progresión temática y derivaciones inferenciales propias de la cultura científica, que suele considerarse superior a la cultura popular. Sin embargo, otros fenómenos de literacidad en curso transitan en sentido inverso: la disgregación, brevedad, fragmentación, abundancia y premura asociados a las actuales prácticas de lectura y escritura en línea, gobernadas por modelos de negocio corporativos que hacen de la desinformación y de la opción de "no información" una mercancía rentable, forman parte de las prácticas letradas de los jóvenes, ${ }^{7}$ llegando a perturbar las figuras de literacidad escolar tradicionales. Dichas modalidades diversifican las formas de búsqueda y procesamiento de información, la interpretación de datos, la (re)creación de universos de sentido y de acción por parte de los estudiantes. Son prácticas de lectura y escritura que tienen lugar en mercados de información desrregulados, destinadas no solo para establecer fugaces procesos de sociabilidad, consumo y creatividad mediante dispositivos tecnológicos móviles, sino que participan en el ejercicio de ciudadanía, ${ }^{8}$ la generación de emociones, construcción de identidades, subjetividades y conocimientos compartidos y los considerados válidos. ${ }^{9}$ Semejante escenario plantea desafíos notables para las instituciones educativas, especialmente en lo que concierne a proce-

evento, demostrar conocimientos relevantes y socialmente valorados y producir y manipular a la escritura y sus convenciones": Kalman, J. (1993). En búsqueda de una palabra nueva: la complejidad conceptual y las dimensiones sociales de la alfabetización. Revista Latinoamericana de Estudios Educativos, XXIII(1), 87-95.

6 La tendencia a escolarizar todo tipo de literacidad implica considerar este tipo como modelo a seguir, el desdibujamiento progresivo de fronteras entre diferentes tipos de literacidades y la devaluación de otros modelos distintos. Mauger (2004). El retroceso de la lectura. Cuatro hipótesis. En Lahire, B. (comp.). Sociología de la lectura. Barcelona: Gedisa. Por pedagogización o escolarización de la literacidad se entiende la progresiva asociación de las diversas prácticas letradas con las nociones educativas institucionalizadas de enseñanza y aprendizaje. Street, B; J. Street (2004). La escolarización de la literacidad. En Zavala, V.; M. Niño-Murcia; P. Ames (eds.) (2004). Escritura y sociedad. Nuevas perspectivas teóricas y etnográficas. Perú: Pontificia Universidad Católica del Perú/Universidad del Pacífico. La escuela tiende a escolarizar todo tipo de literacidad.

7 Cf. Boyadjian, J. (2021). ¿Desinformación, no información o sobreinformación? Las lógicas de exposición a la actualidad en los entornos estudiantiles. Réseaux, (0). https://doi.org/10.3917/res.222.0021

8 García Canclini, N. (2019). Ciudadanos reemplazados por algoritmos. Alemania: Universidad de Guadalajara/CALAS Maria Sybilla Merian Center. 9 Destacan en este plano cuestiones referidas a lo que se ha llamado postverdad, un cierto grado de indiferencia hacia los hechos, a favor de sentimientos y emociones en los procesos de producción social de conocimiento. Cf. Kempner, J. (2020) Post-truth and the Production of Ignorance. Sociological Forum, 35(1), 234-240. Zembylas, M. (2020). The Affective Grounding of Prost-truth: Pedagogical Risks and Transformative Possibilities in Countering Post-truth Claims. Pedagogy, Culture \& Society, 28(1), 77-92. 
sos de formación docente, cuyas condiciones de trabajo se han visto además afectadas por la situación de pandemia de Covid 19, que ha obligado al uso intensivo de tecnologías digitales en las prácticas de literacidad escolares.

Finalmente, respecto a los planes y programas de fomento a la lectura dirigidos a la población en general, permanecen interrogantes sobre el horizonte de expectativas en el corto y mediano plazos. ¿Es deseable una recomposición de las estrategias seguidas hasta ahora para potenciar su capacidad y pertinencia en el presente contexto social? ¿Optarán por jugar un papel más comprometido para promover prácticas de lectura $-y$, deseablemente, de escrituracomo vectores de participación y agencia social y no solo la facilitación del acceso a ciertos materiales? Un giro de estas características puede parecer difícil; no obstante, es cada vez más clara la necesidad de adoptar estrategias de fomento articuladas con las expectativas, propósitos, búsquedas, costumbres, valores y normas culturales de quienes ahora se visualizan solo como "beneficiarios" de ellas. Para este efecto, los estudios empíricos de tipo cualitativo sobre prácticas de lectura y escritura efectuadas en comunidades y contextos socioculturales específicos, permiten su mejor comprensión. Los conocimientos que aportan resultan imprescindibles para desmontar el aún persistente "mito de la lectura" que la presenta de modo simplificado, como un espectro predeterminado de habilidades independientes del contexto, pivote de superación personal y mejoramiento social (Graff, 2010). ${ }^{10}$ Sin duda, al controvertir la visión individualista y descontextualizada de literacidad, se cuestionan asimismo las distinciones jerárquicas arbitrarias que aún prevalecen acerca de determinadas competencias, contenidos y formatos, lo que deriva frecuentemente en abusivos procesos de homologación cultural, por lo general socialmente asimétricos y, en ocasiones, llanamente discriminatorios.

Los educadores cumplirán un papel decisivo en ampliar las posibilidades de cambio y proseguir, en diálogo con otros campos de conocimiento, la reflexión colectiva sobre los paradigmas que subyacen y guían las producciones socioculturales de la literacidad. Y, si como se ha afirmado, mediante las prácticas de lectura y escritura, los sujetos y las comunidades entretejen la incesante urdimbre de comunicación, relaciones de poder, ejercicio de derechos y justicia social en nuestras sociedades, corresponde a los programas orientados a su fomento dar cuenta de ello.

10 Graff, H. J. (2010). The Literacy Myth at Thirty. Journal of Social History, 43(3), 635-661. 